\title{
Conhecimento Científico em Biotecnologia de estudantes do Ensino Médio de escolas públicas na Zona Oeste do Rio de Janeiro
}

\section{Scientific knowledge on Biotechnology among high school students of public schools from the West Zone of Rio de Janeiro/RJ}

\author{
${ }^{1}$ Ida Carolina Neves Direito \\ 1,2 Ronaldo Figueiró \\ 2,3 Marcelo Paraíso Alves \\ ${ }^{1}$ Antonio Marcos Dias de Oliveira \\ ${ }^{1}$ Marise Costa de Mello \\ ${ }^{1}$ Maria Rita Guinancio Coelho \\ ${ }^{1}$ João Bosco de Salles \\ ${ }^{1}$ Jessica Manya Bittencourt Dias Vieira \\ ${ }^{1}$ Luciana Portal da Silva \\ ${ }^{4}$ Tatiana Nascimento Docile \\ ${ }^{1}$ Maria Cristina de Assis
}

\section{RESUMO}

A educação científica e tecnológica aos estudantes de ensino médio deve ser assegurada para que este venha a contribuir de forma crítica e participativa com o desenvolvimento da sociedade. O presente trabalho foi realizado entre estudantes de ensino médio de escolas públicas da zona oeste do município do Rio de Janeiro/RJ visando observar o conhecimento destes estudantes acerca do tema biotecnologia. Os alunos foram convidados a responder a um formulário e a participar das oficinas experimentais do projeto. Observamos que os temas tratados por ações públicas e/ou pela mídia são mais próximos da realidade dos alunos, como a Dengue e a reciclagem; enquanto que o conhecimento sobre assuntos relacionados à microbiologia e à química são dependentes das ações realizadas nas escolas, mais especificamente pelos professores.

Palavras-chave: educação científica, educação tecnológica, biotecnologia

\section{ABSTRACT}

The science and technology education to high school students should be to ensure for their critical and participatory contribution to the development of society. This study was conducted among high school students from public schools in the west of Rio de Janeiro / RJ to analyze their knowledge on the topic biotechnology. Students were asked for answers end invited to participate in the experimental project workshops. We note that the topics covered by public actions and/or for the media are closer to the reality of students, such as Dengue fever and recycling; while the knowledge about issues related to microbiology and chemistry are dependent on the actions performed in schools, specifically by teachers.

Keywords: science education, technology education, biotechnology

\footnotetext{
1 Centro Universitário Estadual da Zona Oeste

2 Centro Universitário de Volta Redonda (UniFOA)

Instituto Federal de Educação, Ciência e Tecnologia do Rio de Janeiro, Campus Volta Redonda

4 Universidade Federal do Rio de Janeiro (UFRJ) / Programa de Pós Graduação em Ecologia
} 


\section{INTRODUÇÃO}

A razão cognitivo industrial - tecnológica tornou-se, a partir do projeto de modernidade, a referência do pensamento ocidental, determinando hegemonicamente modos de compreensão do mundo e produzindo a exclusão e invizibilização de diversos saberes (SANTOS, 2002; 2010). Nas últimas décadas transformou-se na base da globalização acarretando consequências imediatas em nossas vidas pessoais e profissionais. O impacto deste modo de compreensão emerge na sociedade atual como o centro de todas as formas de desenvolvimento, influenciando o desenvolvimento econômico, o que lhe confere a legitimidade e hegemonia diante dos outros saberes (ZIBAS, 2006).

Tal racionalidade considera que o desenvolvimento de um país está relacionado diretamente à educação e à formação dos sujeitos que a compõem, pois enquanto países desenvolvidos investem recursos financeiros e humanos no processo educacional, outros ainda persistem na importação de tecnologia e de equipamentos como ações estratégicas de desenvolvimento.

Um exemplo clássico dos aspectos supracitados emerge na reforma do Ensino Médio no Brasil a partir da década de 1990, mais especificamente por intermédio dos Parâmetros Curriculares Nacionais (PCN), um dos braços da reforma. O documento, apesar de propor a reorganização curricular baseada na integração, na interdisciplinaridade e na contextualização, se apresenta enredada aos princípios neoliberais (FMI e Banco Mundial) (FRIGOTTO; CIAVATTA, 2003).

Se por um lado o Ministério da Educação evidencia no PCN que, visa formar um ensino generalista, polivalente e flexível, utilizando as competências e habilidades, para propor um currículo onde a tecnologia (ou tecnologias) tenha um papel integrador entre as disciplinas e/ou áreas. De outro lado, busca a inserção do país na nova ordem mundial, por intermédio da educação, propondo que além da transmissão dos conteúdos escolares, a escola forme o cidadão plural e flexível, capaz de atender as demandas do capitalismo: economia flexível. Notese que, nessa nova ordem, as condições necessárias para incorporação do Brasil nessa realidade são as seguintes: conhecimentos elementares e princípios que aceitem e, mais do que isso, em nome da chamada equidade, pactuem com a racionalidade do capital, cujo componente intrínseco é a desigualdade social entre pessoas ou países (FREIRE, 2007).

A resolução do Conselho Nacional de Educação (CNE) n¹5/98 que trata das Diretrizes Curriculares Nacionais para o Ensino Médio na sessão sobre o "Sentido do Aprendizado das Ciências da Natureza, da Matemática e das Tecnologias”, busca uma proposta para o Ensino Médio sem ser profissionalizante, mas que efetivamente propicie um aprendizado útil à vida e ao trabalho, com uma visão da educação média de caráter amplo, de forma que os aspectos e conteúdos tecnológicos associados ao aprendizado científico e matemático se tornem parte essencial da formação cidadã de sentido universal e não necessariamente, de sentido profissionalizante.

Os objetivos da educação média em cada área do conhecimento devem envolver, de forma combinada, o desenvolvimento de conhecimentos práticos, contextualizados, que respondam às necessidades da vida contemporânea, e o desenvolvimento de conhecimentos mais amplos e abstratos, que correspondam a uma cultura geral e uma visão de mundo (BRASIL - SEMTEC/MEC, 1998).

Para a Área de Ciências da Natureza, Matemática e Tecnologias, isto foi particularmente verdadeiro, pois a crescente valorização do conhecimento e da capacidade de inovar demandou cidadãos capazes de aprender continuamente, para o que é essencial uma formação geral e não bastando um treinamento específico (PINHEIRO et al., 2007).

Para Faria Filho (2004) essa tônica emerge do Relatório Jaques Delors (1999) - (UNESCO) - que defende que o mundo capitalista caminha em direção à efemeridade, portanto, ao instantâneo e por isso torna-se neces- 
sária uma educação que produza um indivíduo que busque soluções rápidas: “uma 'sociedade educativa’ na qual indivíduos tenham 'educação ao longo da vida', ou seja, que possam aprender tanto na escola quanto em todos os momentos da vida”.

Portanto, o autor conclui seu trabalho afirmando que as reformas do estado e da educação ocorridas na década de 1990, buscou a ênfase na eficiência do funcionamento das instituições escolares e na qualidade de seus resultados. Mediante este cenário a educação assumiu papel significativo na formação de um cidadão marcado pelo consumo e pela flexibilização das relações sociais e do trabalho, compatíveis com a flexibilização do capital.

Galvanin (2005) confirma tal panorama tecendo o seguinte comentário:

As relações capitalistas de produção passam a incorporar o cotidiano escolar ao assimilar propostas do Banco Mundial na formulação das políticas educacionais, observados através de critérios como eficiência, eficácia, produtividade - bem como conceitos de empregabilidade, competência, e conduzem a escola como obrigação de preparar para o mercado de trabalho. Idéias de descentralização das ações estatais na educação e incorporação da forma de gestão utilizada pela iniciativa privada remetem os países a reformas estruturais.

Diante do panorama exposto cabe perguntar: qual o papel da universidade no referido contexto? Nesta perspectiva, a produção de conhecimento buscou colaborar com tal paradigma (neoliberal), divulgando conhecimentos sobre diferentes tecnologias. É importante que se perceba que, tal ótica, neoliberal e a referida concepção de tecnologia, partia da noção de desenvolvimento sustentável. Porém, percebemos uma contradição interna em tal conceito, pois apesar de reconhecer os limites para a ação socioambiental, busca uma utópica harmonia entre desenvolvimento econômico, social e a manutenção do ambiente.

Tal contradição potencializa-se ao considerarmos que o atual modo de produção capitalista, traz em seu bojo a concepção de desenvolvimento significando crescimento econômico, fundado no lucro, tendo como centralidade a exploração humana e da natureza.

Porém, o conceito que buscamos para balizar o referido estudo é a sustentabilidade, que está forjada a partir da ideia de preservação e conservação da natureza, tendo como princípio o uso racional dos recursos e da qualidade de vida.

Portanto, pensar um conhecimento científico relacionado ao investimento na pesquisa de novas tecnologias, especialmente a biotecnologia requer caminhar a partir de tal perspectiva (sustentabilidade). Cabe esclarecer que biotecnologia é uma área em desenvolvimento no Brasil, que abrange indústrias como a alimentícia, a química e a farmacêutica, e busca tecnologias que minimizem o impacto das atividades humanas sobre o meio ambiente empregando recursos de origem biológica.

Assim, cabe salientar que a exploração do meio ambiente como fonte de organismos com potencial biotecnológico e que permitam uma sustentabilidade planetária é estimulada pela Política de Biotecnologia para Proteção e Desenvolvimento (Decreto no 6.041 de 08/02/2007): “a noção de sustentabilidade implica, portanto, uma inter-relação necessária de justiça social, qualidade de vida, equilíbrio ambiental e a premente ruptura com o atual padrão de desenvolvimento" (JACOBI, 2003).

Trazer para o estudo tal noção torna-se fundamental, pois cresce a cada dia a busca por novos produtos, que sejam mais eficientes e menos tóxicos, substâncias novas de interesse industrial ou farmacêutico, e tecnologias que permitam minimizar a ação de poluentes no meio ambiente. 
Portanto, noções sobre temas atuais em que se emprega conhecimento tecnológico podem aparecer em vários momentos na escola, nas disciplinas de ciências da natureza, com níveis diversos de enfoque e aprofundamento. É principalmente nas últimas séries do ensino fundamental e no ensino médio que os jovens devem compreender as inter-relações entre o entendimento científico e as mudanças tecnológicas e devem considerar o impacto que as tecnologias podem produzir na sociedade e em decorrência sobre a qualidade de vida.

A parceria universidade/escola pública também aparece como a possibilidade de articular ensino, pesquisa e extensão, o “tripé” no qual se fundamenta a nossa Instituição Universitária, a Fundação Centro Universitário Estadual da Zona Oeste (UEZO). Uma universidade fundada em 2005, criada com a missão de formar mão de obra qualificada para suprir os diversos setores de nossas indústrias, principalmente as localizadas na Zona Oeste do município do Rio de Janeiro - RJ. Propõe o desenvolvimento da sociedade através da difusão da ciência e tecnologia em benefício da própria sociedade. É preciso difundir o conhecimento para conseguir sustentabilidade ambiental. Considerando o exposto e as ressalvas de Guerra (2007), que menciona ser a universidade um importante aliado "na promoção do diálogo e na interação entre o conhecimento e o aperfeiçoamento das práticas docentes", foi desenvolvido um projeto que teve como objetivo agregar o conhecimento acadêmico às instituições educacionais visando: i) desmitificar os microrganismos e apresentar seus potenciais biotecnológicos; ii) estimular, através de atividades práticas e apresentação de material didático específico, os estudantes de ensino médio de escolas públicas da Zona Oeste do município do Rio de Janeiro a ingressarem no contexto tecnológico global de sustentabilidade ambiental; iii) divulgar os hábitos para a prevenção de algumas doenças as quais os jovens são mais suscetíveis. Os estudantes foram convidados a participarem de algumas oficinas temáticas, tendo como pré-requisito o preenchimento de um formulário com questões relacionadas às atividades realizadas nas oficinas. O presente estudo teve como objetivo traçar um perfil dos estudantes de ensino médio de escolas públicas da zona oeste do município do Rio de Janeiro/RJ acerca do tema biotecnologia.

\section{Procedimentos Metodológicos}

O projeto foi estruturado na organização de oficinas temáticas a serem realizadas nas escolas públicas selecionadas. As oficinas foram fundamentadas em três temas básicos (Tabela 1): i) Microbiologia na saúde e na doença; ii) Química no dia a dia; e iii) Meio ambiente. O tema "Microbiologia na saúde e na doença" buscou realizar reflexões sobre a flora residente e a existência de microrganismos patogênicos ao homem, ao mesmo tempo que apresentou os microrganismos benéficos à sociedade através da apresentação da microbiologia ambiental e seu potencial biotecnológico. O tema "Química no dia a dia" levantou a existência e relevância das enzimas, assim como o de processos químicos presentes no nosso dia a dia, como a eletrofloculação. O tema "Meio ambiente" trabalhou a educação ambiental através da reciclagem do lixo e a problemática do lixo como responsável pela proliferação de vetores de doenças, usando como exemplo a dengue.

Foi elaborado um questionário com 35 questões objetivas com respostas dicotômicas (sim ou não) (Tabelas 2, 3 e 4). Este formulário foi entregue a todos os estudantes antes da sua participação no projeto visando traçar um perfil do conhecimento científico sobre biotecnologia usando como base os temas a serem apresentados pelas oficinas. 
Tabela 1: Oficinas temáticas do projeto "Microrganismos e Biotecnologia: Educação para o desenvolvimento tecnológico do futuro”.

\begin{tabular}{|c|c|c|}
\hline Temas & Oficinas & Atividades \\
\hline \multirow[b]{2}{*}{$\begin{array}{l}\text { Microbiologia na } \\
\text { saúde e na doença }\end{array}$} & $\begin{array}{l}\text { Cárie e Doenças } \\
\text { Sexualmente transmissíveis }\end{array}$ & $\begin{array}{l}\text { Visualização ao microscópio de bactérias presentes } \\
\text { na boca. Apresentação ilustrada de DSTs. }\end{array}$ \\
\hline & $\begin{array}{l}\text { Bioprospecção e } \\
\text { biotecnologia de } \\
\text { microrganismos }\end{array}$ & $\begin{array}{l}\text { Visualização ao microscópio de microrganismos } \\
\text { presentes em laticínios comercializados em } \\
\text { supermercados. Fermentação microbiana } \\
\text { usando fermento de pão. Bioprospeç̧ão de } \\
\text { microrganismos do solo. }\end{array}$ \\
\hline \multirow[b]{2}{*}{ Química no dia a dia } & Enzimas & Detecção de pesticidas em frutas. \\
\hline & Eletrofloculação & $\begin{array}{l}\text { Apresentação de um vídeo sobre a presença da } \\
\text { química em nosso dia a dia e debate sobre o } \\
\text { tema. Maquete para mostrar a classificação dos } \\
\text { resíduos, o seu tratamento e a importância da sua } \\
\text { reciclagem para a proteção do meio ambiente. } \\
\text { Experiência química utilizando produtos de uso } \\
\text { doméstico sobre a descontaminação da água por } \\
\text { eletrofloculação. }\end{array}$ \\
\hline \multirow[t]{2}{*}{ Meio ambiente } & Reciclagem do lixo & $\begin{array}{l}\text { Realização da prática da coleta seletiva. } \\
\text { Apresentação de exemplos de reaproveitamento de } \\
\text { garrafas pets como para a confecção de vassouras } \\
\text { e banco. }\end{array}$ \\
\hline & Dengue & $\begin{array}{l}\text { Identificação do mosquito da dengue e } \\
\text { apresentação das armadilhas utilizadas para } \\
\text { monitoramento dos vetores }\end{array}$ \\
\hline
\end{tabular}

Os estudantes que participaram do projeto foram oriundos de escolas públicas selecionadas em função da sua localização, disponibilidade para receberem o projeto e perfil dos egressos em nível de ensino médio. Foram selecionadas 05 escolas públicas de ensino médio localizadas na Zona Oeste do município do Rio de Janeiro RJ. A escola $A$ possui ensino médio profissionalizante na área de ensino e propiciou que todos os seus estudantes cursando o último ano do ensino profissionalizante participassem do projeto que foi realizado na própria escola. As escolas $B$ e $C$ possuem ensino médio profissionalizante com cursos na área de ciências exatas e/ou da computação. As escolas $D$ e $E$ possuem ensino médio regular sem formação profissionalizante. Nas escolas $B$ e $D$ o projeto foi realizado na própria escola nos turnos da manhã e da tarde, sendo as turmas participantes do projeto selecionadas pelas escolas. A realização do projeto com as escolas $C$ e $E$ foi realizada nos laboratórios da UEZO com a recepção das turmas de alunos selecionadas pelas escolas. Todos os grupos de alunos sempre foram acompanhados por pelo menos um professor responsável.

\section{RESULTADOS E DISCUSSÃO}

Participaram do projeto 819 alunos cursando o ensino médio e matriculados em uma das cinco escolas públicas da Zona Oeste do Rio de Janeiro selecionadas. A escola $A$ participou com 380 alunos. A escola $B$ com 229, enquanto a escola $C$ com 48 alunos. Na escola $D, 107$ alunos participaram do projeto e, na escola $E$, 55 alunos. 
Nossos resultados foram obtidos a partir da análise das respostas às questões do formulário. As respostas obtidas às questões sobre o tema "Microbiologia na saúde e na doença”" (Tabela 03) mostraram que 79,1\% $\pm 10 \%$ dos estudantes tem noção da cárie como uma doença infecciosa, mas apenas $22,4 \% \pm 30 \%$ sabem o que é um biofilme bacteriano e como se forma a placa bacteriana. Quando o assunto é DSTs, $92,2 \% \pm 2,0 \%$ dos alunos conhecem o assunto, mas surpreendentemente apenas $48,9 \% \pm 24,4 \%$ possuem conhecimento sobre vírus e a sua relação com doenças em humanos. Estes jovens desconheciam o vírus HPV e sua relação com câncer de colo de útero, bem como apresentaram conceitos equivocados sobre o vírus HIV, demonstrando que temas de imensa relevância para saúde do adolescente não estão sendo assimilados adequadamente.

Quando abordamos os efeitos benéficos dos microrganismos (questão 6) para o homem, tivemos um percentual médio de respostas afirmativas dos alunos das cinco escolas que participaram do projeto de $55,9 \% \pm 19,9 \%$, demonstrando um menor conhecimento da importância dos microrganismos nos processos ecológicos, industriais e agrícolas em relação ao observado quanto ao conhecimento das doenças causadas por microrganismos (cárie e DSTs). Dentre os jovens pesquisados, $47,5 \% \pm 0,27 \%$ sabiam o que é um lactobacillus e $26,0 \% \pm 0,33 \%$ o que é bioprospecção. Estes resultados podem sugerir tanto uma maior ênfase do ensino nestas escolas aos microrganismos patogênicos, assim como o interesse inerente ao conhecimento do próprio corpo pelo adolescente. Segundo Villas Boas \& Souza Moreira (2012), os livros didáticos adotados no ensino médio de Lavras - Minas Gerais para o ensino de Biologia para o ensino médio apresentam maior ênfase aos microrganismos patogênicos do que a sua importância para o solo, a agricultura e o meio ambiente. Independentemente da razão pela qual alunos do ensino médio não estejam familiarizados com microrganismos benéficos, para o desenvolvimento do cidadão crítico e do desenvolvimento da sociedade é importante que a temática de biotecnologia seja trabalhada mais amplamente na escola.

Tabela 2: Perguntas das oficinas do tema “ Microbiologia na saúde e na doença”.

1- Você sabe o que é um biofilme bacteriano ?

2- Você tem conhecimento que a cárie é uma doença infecciosa?

3- Sabe o que significa DST?

4- A gonorréia é uma DST?

5- Você sabia que o câncer de colo de útero pode ser uma consequência de infecção por HPV (papilomavírus humano)?

6- Você conhece bactérias ou fungos bons para a saúde?

7- Você já viu os Lactobacillus?

8- Você acha que estudando o solo/meio ambiente podemos encontrar novos produtos para ajudar no dia a dia?

9- Você come bactérias?

10- Você já ouviu falar em bioprospecção?

Observamos durante a realização das oficinas que a maioria dos alunos nunca tinham tido contato com um microscópio, nem sequer visto uma bactéria. Foi muito interessante observar a reação dos alunos ao visualizarem os lactobacilos do iogurte ao microscópio. Ao final do trabalho, os estudantes não somente passaram a conhecer o processo da formação da placa bacteriana na cárie, bem como o papel de microrganismos no meio ambiente e seu potencial biotecnológico. Ter uma noção de como operam os níveis de vida microscópicos e submicroscópicos da biologia é um pressuposto para uma compreensão mínima da biotecnologia contemporânea.

A análise das respostas das questões das oficinas referente ao tema "Química no dia a dia” (Tabela 3) nos revelaram que $84.4 \% \pm 6,4 \%$ dos alunos que responderam ao formulário compreendem a importância das reações 
químicas no cotidiano, no entanto, apenas $49,5 \% \pm 22,1 \%$ conhecem as maneiras de descartes de resíduos, principalmente os químicos.

Tabela 3: Perguntas das oficinas do tema “Química no dia a dia”.

11-A química faz parte do seu cotidiano?

12- A química prejudica o meio ambiente?

13- Você conhece as maneiras de descartar os resíduos, principalmente os resíduos químicos?

14- A química pode ser utilizada para cuidar do meio ambiente?

15- Você sabe o que é eletrofloculação?

16- Você sabe o que são pesticidas?

17- Você sabe o que são enzimas?

18- Você sabe o que são bioindicadores de poluição?

19- Você sabe o que são biomarcadores de poluição?

20- Você sabe como evitar a intoxicação com pesticidas presentes na superfície de frutas, legumes e verduras?

21- No Colégio onde você estuda são realizadas aulas práticas da disciplina de química?

22- São realizados experimentos simples em sala de aula?

23- Existe laboratório de química em sua escola?

24- Você sente dificuldade em entender alguns tópicos teóricos de química?

25- Acha que experimentos facilitariam o seu aprendizado?

Quando foram abordados sobre o processo de eletrofloculação, processo simples e que pode ser facilmente demonstrado em sala de aula, apenas $10,5 \% \pm 5,1 \%$ do total de alunos das escolas $A, B, C$ e $E$ conheciam o processo. Surpreendente $76,9 \%$ dos alunos da escola $D$ conheciam este processo. Analisando outras características da escola $D$, acreditamos que estes alunos possuem maior acesso a estes temas, tendo em vista que esta escola possui projetos desenvolvidos em parceria com universidades e institutos de pesquisa. Esta hipótese é corroborada quando avaliamos o assunto bioindicadores e biomarcadores de poluição a partir do percentual médio obtido das respostas afirmativas dos dois temas que foi $30,6 \% \pm 21,4 \%$, nas escolas $A, B, C$ e $E$ contra $85,95 \%$ na escola $D$.

Outra abordagem realizada neste tema foi obter a opinião dos alunos sobre a prática de experimentos nas aulas de química e a importância desta prática para estimular o aprendizado. Os resultados mostraram que os alunos têm consciência da importância das aulas experimentais como facilitadoras de seu aprendizado, pois $88,8 \% \pm 3,0 \%$ dos alunos responderam afirmativamente a questão de número 25 (Tabela 3 ). Os resultados gerados pelas respostas afirmativas à questão de número 21 mostraram que nas escolas $A, B$ e $E 21,7 \% \pm 8,1 \%$ dos alunos informaram que são realizadas aulas práticas para o ensino de química, enquanto que na escola $C$ foi observado $73,5 \%$ das respostas afirmativas e, na escola $D, 50 \%$ de respostas afirmativas. Quando questionados se eram realizados experimentos simples em sala de aula, $43,6 \% \pm 1,2 \%$ dos alunos das escolas $A, B$ e $D$ responderam que sim, enquanto que na escola $C$ a questão teve $84,6 \%$ das respostas afirmativas e, na escola $E$, apenas $12,7 \%$. A resposta à questão 23 mostrou que $55,7 \% \pm 30,7 \%$ dos alunos tinham conhecimento sobre a existência de laboratório na escola. $\mathrm{O}$ valor de desvio padrão elevado mostra que foi bem variada a resposta a esta questão pelos alunos das diferentes escolas. Foi possível observar que mesmo nas escolas que possuem a infra-estrutura de Laboratório (escolas $A, B, C$ e $E$ ) muitos dos alunos desconheciam a sua existência. Embora já tenha decorrido 
mais de uma década da promulgação da Lei de Diretrizes e Bases da Educação Nacional-LDB N 9394 de 20 de dezembro de 1996, quase nada mudou em relação ao desenvolvimento de práticas pedagógicas que promovam uma Alfabetização Científica e Tecnológica. As respostas dos alunos nas diferentes escolas às questões 21, $22 \mathrm{e}$ 23 nos levam a crer que a realização de aulas práticas para o aprendizado da química está relacionada à iniciativa do professor, independentemente do perfil dos alunos egressos e da infra-estrutura da escola.

Quanto ao tema "Meio ambiente", os alunos que participaram do projeto apresentaram um bom conhecimento sobre a dengue e reciclagem ao responderem aos questionamentos do formulário (Tabela 4). Dos alunos que participaram do projeto, $93,2 \% \pm 4,2 \%$ responderam que sabem o que é coleta seletiva e $95,4 \% \pm 3,3 \%$ responderam que sabem o que é reciclagem. Quanto às questões sobre a dengue, $83,7 \% \pm 6,3 \%$ dos alunos responderam que sabem identificar o mosquito transmissor da Dengue e $93,6 \% \pm 2,4 \%$ responderam que sabem que o lixo pode acumular água e servir de criadouro para as larvas do mosquito da Dengue. Acreditamos que isso possa ser um reflexo do fato destes temas serem amplamente explorados na mídia, bem como alvo de diferentes campanhas pelos órgãos públicos, por estarem diretamente relacionados com a saúde público e o desenvolvimento sustentável. Por esta mesma razão, acreditamos que estes temas chamaram muito a atenção dos alunos que aproveitaram a oportunidade para tirarem dúvidas e buscarem esclarecimentos sobre situações do dia a dia relacionadas aos temas abordados pelos projetos.

Tabela 4: Perguntas das oficinas do tema "Meio ambiente".

26- Você sabe o que é Coleta Seletiva?

27- Você sabe o que são resíduos?

28- Você sabe o que é reciclagem?

29- Você sabe como minimizar o descarte inadequado de nossos resíduos?

30- Você sabe como podemos melhorar o nosso lixo?

31- Você sabe como a Dengue é transmitida?

32- Você sabe identificar o mosquito transmissor da Dengue?

33- Você sabe que o lixo pode acumular água e servir de criadouro para as larvas do mosquito da Dengue?

34- Você sabe o horário de atividade do mosquito da Dengue?

35- Você consegue diferenciar o mosquito comum do mosquito da Dengue?

\section{CONSIDERAÇÕES FINAIS}

A educação é o caminho para toda mudança, para a mobilização e para a formação de uma consciência crítica. Essa afirmação tem base nos impactos sociais originados pela Ciência e Tecnologia, fornecendo assim uma consciência pertinente à participação pública e social efetiva. Para que esse fundamento possa surtir efeito no ensino, precisamos, necessariamente, da formação de profissionais capacitados. Tendo em vista que os professores são agentes centrais das mudanças efetivas dos sistemas educativos recai sobre as instituições de formação de professores a responsabilidade na assessoria e no apoio aos professores nos seus processos de mudança, desenvolvimento e atualização.

Os professores têm um importante papel no auxílio à comunidade na compreensão das tecnologias. Portanto, somente quando a alfabetização em Ciência e Tecnologia for entendida neste contexto mais amplo, poderá existir 
uma esperança real de que a configuração do nosso mundo futuro seja traçada por um eficiente controle público, de modo que os processos científicos e tecnológicos beneficiem verdadeiramente a humanidade (BAZZO, 1998).

A biotecnologia faz parte de nosso dia a dia e acreditamos que com estratégias simples é possível estimular o aluno a pensar, a contextualizar conteúdos curriculares e científicos com seu cotidiano, de maneira a formar um individuo crítico, interessado e que possa ter despertado suas competências visando seu futuro profissional. Da mesma forma, é através da educação destes jovens em sincronia com o desenvolvimento científico-tecnológico da sociedade que teremos cidadãos capazes de refletirem sobre as questões sociais decorrentes do avanço tecnológico.

\section{AGRADECIMENTOS}

À Fundação Carlos Chagas Filho de Amparo à Pesquisa no Estado do Rio de Janeiro (FAPERJ).

\section{REFERÊNCIAS BIBLIOGRÁFICAS}

BAZZO, W. A. Ciência, tecnologia e sociedade e o contexto da educação tecnológica. Florianópolis: UFSC, 1998. $319 \mathrm{p}$.

BRASIL Secretaria de Ensino Médio e Tecnológico do Ministério de Educação (SEMTEC/MEC) - Proposta Preliminar para a Área das Ciências da Natureza, da Matemática e das suas Tecnologia no Ensino Médio. Brasília: SEMTEC/MEC, 1998.

EC 6.041/2007 (DECRETO DO EXECUTIVO) 08/02/2007. Institui a política de desenvolvimento da biotecnologia, cria o Comitê Nacional de Biotecnologia e dá providências. D.O.U de 09/02/2007, P1.

FARIA FILHO, Luciano Mendes de et al. A cultura escolar como categoria de análise e como campo de investigação na história da educação brasileira.Educação e pesquisa, v. 30, n. 1, p. 139-159, 2004.

FREIRE, L. I. F. Pensamento crítico, enfoque educacional CTS e o ensino de química. 2007. 175 p. Tese. (Doutorado em Educação Científica e Tecnológica) - Programa de Pós-graduação em Educação Científica e Tecnológica, Universidade Federal de Santa Catarina, Florianópolis, 2007. Disponível em: <http://www.tede. ufsc.br/teses/PECT0057-D.pdf>.

FRIGOTTO, Gaudêncio; CIAVATTA, Maria. Educação básica no Brasil na década de 1990: subordinação ativa e consentida à lógica do mercado.Educação e sociedade, v. 24, n. 82, p. 93-130, 2003.

GALVANIN, B. Reforma do sistema educacional dos anos 90: breves considerações sobre os aspectos históricos, econômicos, e políticos. Hórus - Revista de Humanidades e Ciências Sociais Aplicadas, Ourinhos/SP, nº 03, 2005.

GUERRA, A. F. S. Formação continuada de educadores ambientais: desafios e possibilidades. In: RAITZ, T. R.; FERREIRA, V. S; GUERRA, A. F. S. (Orgs.). Ética e Metodologia: pesquisa na Educação. Itajaí: UNIVALI, 2007, p. $241-255$.

JACOBI, P. Educação ambiental, cidadania e sustentabilidade. In: Cadernos de Pesquisa. n.118. São Paulo: Autores Associados, 2003. p. 189-205.

LEI 9.394/1996 (LEI ORDINÁRIA) - 20/12/1996. Estabelece as Diretrizes e Bases da Educação Nacional LDB. D.O. de 23/12/1996. P27833. 
PINHEIRO, N. A. M.; SILVEIRA, R. M. C. F; BAZZO, W. A. Ciência, tecnologia e sociedade: a relevância do enfoque CTS para o contexto do ensino médio. Ciência \& Educação. São Paulo, v. 13, v. 1, p. 71-84, 2007.

SANTOS, W. L. P. Contextualização no ensino de ciências por meio de temas CTS em uma perspectiva crítica. Ciência \& Ensino. São Paulo, v. 1, número especial, nov. 2007.

SANTOS, W. L. P.; MORTIMER, E. F. Uma análise de pressupostos teóricos da abordagem C-T-S (Ciência Tecnologia - Sociedade) no contexto da educação brasileira. ENSAIO - Pesquisa em Educação em Ciências.v. 2, n. 2, dez. 2002.

VILAS BOAS, R.C; MOREIRA, F M S. Microbiologia no solo no ensino médio de Lavras- MG- Revista Brasileira de Ciência do Solo. 36: 295-306. 2012.

ZIBAS, Dagmar. A reforma do ensino médio nos anos de 1990: o parto da montanha e as novas perspectivas. Associação Nacional de Pós-Graduação e Pesquisa em Educação, 2006. 